\title{
Modeling of Development Scenarios of Critically Important Objects for Support of Adoption of Scientifically Based Decisions*
}

\author{
Larisa A. Ginis ${ }^{1}$, Anna E. Kolodenkova ${ }^{2}$ \\ ${ }^{1}$ Southern Federal University \\ Taganrog, Russia \\ e-mail: gla@sfedu.ru \\ ${ }^{2}$ Ufa State Aviation Technical University \\ Ufa, Russia \\ e-mail: anna82_42@mail.ru
}

\begin{abstract}
Cognitive and simulation modeling is applied to research the behavior of critically important objects. The fuzzy cognitive model of the organizational-control structure of the object under study is proposed. A computer experiment is carried out, the development scenarios of the object are modeled under the conditions of various disturbances
\end{abstract}

Keywords- critically important objects; decision-making, modeling, scenarios

\section{INTRODUCTION}

Adequate mathematical mapping of the surrounding world to accept scientific-reasonable decisions in problematic situations is one of the fundamental problems in the field of modern modeling and development of decision support intelligence technologies.

Recently, there has been a stable interpretation of the term "Critically important object" (CIO) under which objects are understood, the violation and/or the interruption of functioning of which results in a minimum of problems in the safety of the vital activity of the population, destruction of the infrastructure, and as a maximum, to irreversible changes in the economics of the individual subject/industry/country. Therefore the problem of ensuring security of $\mathrm{CIO}$ and the population from influence of such factors as the negative impact of natural, technogenic and terrorist character and/or loss of their management is relevant, and development of models, methods, algorithms for development of scientifically based decisions on steady functioning of $\mathrm{CIO}$ and to decision-making in problem situations is the important direction of modern applied modeling to which enough works in Russia and abroad is devoted [1-5].

\section{Problem Definition}

Now in the territory of the Russian Federation about 4,5 thousand CIO among which the nuclear power plants (NPP) hold a specific place function, this is the subject of the study in this work. Constant increase of the volumes of the obtained and stored, heterogeneous information is the characteristic of the named object of the investigation. However, formalized approaches are required for processing such information and for taking a timely solution from the evaluation of the current situation under the conditions of CIO monitoring. The pronounced system character of this problem determines the need to develop a certain complex of models and methods, which is able to provide support of decision-based control decisions. This is why we propose the use of a cognitivesimulation apparatus.

\section{DEVELOPMENT AND RESEARCH OF MODEL}

The analysis of open information sources has led to definition of model concepts, by means of experts the generalized organizational-control fuzzy cognitive model of the NPP is developed (Fig. 1).

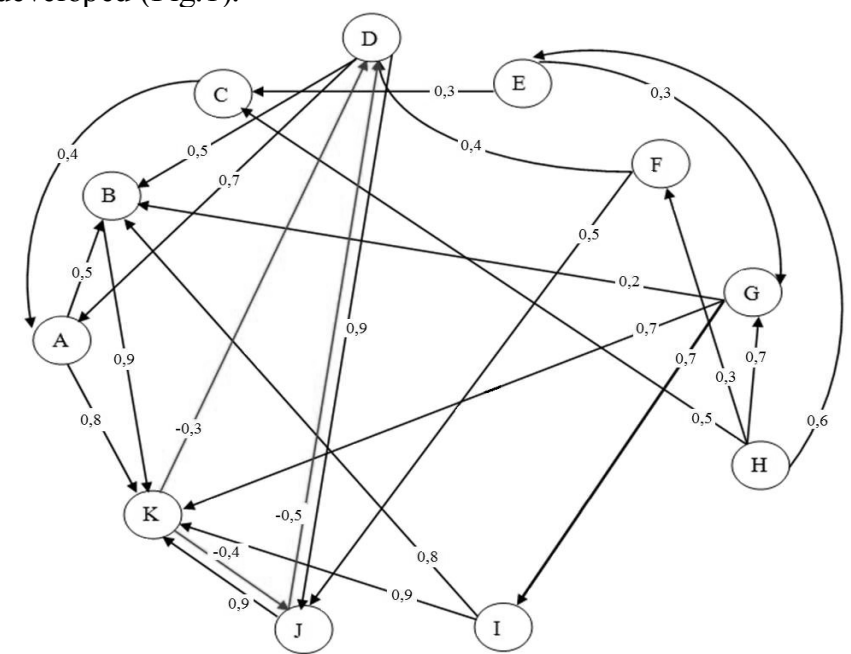

Fig. 1. The fuzzy cognitive model of the NPP organizational-control structure

*This work has been supported by the Ministry of Education and Science of the Russian Federation under Project "Methods and means of decision making on base of dynamic geographic information models" (Project part, State task 2.918.2017/4.6); and the Russian Foundation for Basic Research, Projects № 1607-00335, 16-07-00336, 17-08-00402 
List of concepts: A $\left(x_{1}\right)$ - the monitoring system of operational data of the NPP (regarding radiation and fire monitoring of an object); $\mathrm{B}\left(x_{2}\right)$ - the decision-making speed; $\mathrm{C}$ $\left(x_{3}\right)$ - innovative technologies of tracking and control, introduction of modern information technologies (IT) minimizing risk of a human factor (the automated human-machine systems); $\mathrm{D}\left(x_{4}\right)$ - a human factor (qualification of personnel, education level, technological culture); E $\left(x_{5}\right)$ - updating coefficient equipment; $\mathrm{F}\left(x_{6}\right)$ - specifications and technical documentation improvement; $\mathrm{G}\left(x_{7}\right)$ - working capacity and system effectiveness of reserve power supply; $\mathrm{H}\left(x_{8}\right)$ - investments (state financing); I $\left(x_{9}\right)$ - the combat readiness level and fire scheduled maintenance of object fire divisions; $\mathrm{J}\left(x_{10}\right)$ - personal responsibility of employees; K $\left(x_{11}\right)$ - NPP safety.

\section{A. Stability Model}

The analysis of the developed model on stability is the following stage of modeling. It is suggested to examine the developed model for structural stability as follows. In this work, the fuzzy cognitive model (FCM) is fuzzy directed graph of the first kind. So, the fuzzy cognitive model is a [6] pair of sets $\widetilde{G}=(X, \widetilde{U})$ in which $X=\left\{x_{i}\right\}, i \in I=\{1,2, \ldots, \mathrm{n}\}$ is a crisp set of vertices (or concepts), and $\left.\widetilde{U}=\left\{<\mu_{U}<x_{i}, x_{k}>/<x_{i}, x_{k}\right\rangle>\right\}$ is a fuzzy set of edges (or arcs), where $<x_{i}, x_{k}>\in X^{2}$, and $\mu_{U}<x_{i}, x_{k}>$ is a degree of membership oriented edge $<x_{i}, x_{k}>$ to fuzzy set of directed edges $\widetilde{U}$.

To determine the stability of the FCM, it is possible to apply the approach described in [7] and associated with finding the eigenvalues of the weighted orgraph, however, in the case of an fuzzy model, it is believed that this approach is not reasonably correct. It is suggested to research the stability model by determining the vitality degree of an fuzzy graph under which we will understand the degree of structural stability of the model under investigation. We will consider the vitality degree of fuzzy graph as a degree of strong connection, so it will be defined by the formula $V(\widetilde{G})=\underset{x_{i} \in X}{\&} \underset{x_{j} \in X}{\&} \tau\left(x_{i}, x_{j}\right)$. [8] and can be determined through the strong connectivity degree in case of fulfillment of the condition: $\left(\forall x_{i} \in X\right)\left(S_{\Gamma\left(x_{i}\right)}=X\right)$, where $\stackrel{\mathcal{L}}{\Gamma}\left(x_{i}\right)$ - fuzzy transitive closure. In detail the algorithm is described in [8]. The algorithm has been realized for the studied model. Adjacent matrix:

$$
A=\left[\begin{array}{ccccccccccc}
0 & 0,5 & 0 & 0 & 0 & 0 & 0 & 0 & 0 & 0 & 0,8 \\
0 & 0 & 0 & 0 & 0 & 0 & 0 & 0 & 0 & 0 & 0,9 \\
0,4 & 0 & 0 & 0 & 0 & 0 & 0 & 0 & 0 & 0 & 0 \\
0,7 & 0,5 & 0 & 0 & 0 & 0 & 0 & 0 & 0 & 0,9 & 0 \\
0 & 0 & 0,3 & 0 & 0 & 0 & 0 & 0 & 0 & 0 & 0 \\
0 & 0 & 0 & 0,4 & 0 & 0 & 0 & 0 & 0 & 0,5 & 0 \\
0 & 0,2 & 0 & 0 & 0 & 0 & 0 & 0 & 0,7 & 0 & 0,7 \\
0 & 0 & 0,5 & 0 & 0,6 & 0,3 & 0,7 & 0 & 0 & 0 & 0 \\
0 & 0,8 & 0 & 0 & 0 & 0 & 0 & 0 & 0 & 0 & 0,9 \\
0 & 0 & 0 & -0,5 & 0 & 0 & 0 & 0 & 0 & 0 & 0,9 \\
0 & 0 & 0 & -0,3 & 0 & 0 & 0 & 0 & 0 & -0,4 & 0
\end{array}\right]
$$

Reachability matrix:

$$
\gamma=\left[\begin{array}{ccccccccccc}
1 & 0,5 & 0 & 0,4 & 0 & 0 & 0 & 0 & 0 & 0,4 & 0,8 \\
0,4 & 1 & 0 & 0,4 & 0 & 0 & 0 & 0 & 0 & 0,4 & 0,9 \\
0,4 & 0,4 & 1 & 0,4 & 0 & 0 & 0 & 0 & 0 & 0,4 & 0,4 \\
0,7 & 0,5 & 0 & 1 & 0 & 0 & 0 & 0 & 0 & 0,9 & 0,9 \\
0,3 & 0,3 & 0,3 & 0,3 & 1 & 0 & 0 & 0 & 0 & 0,3 & 0,3 \\
0,5 & 0,5 & 0 & 0,5 & 0 & 1 & 0 & 0 & 0 & 0,5 & 0,5 \\
0,4 & 0,7 & 0 & 0,4 & 0 & 0 & 1 & 0 & 0,7 & 0,4 & 0,7 \\
0,4 & 0,7 & 0,5 & 0,4 & 0,6 & 0,3 & 0,7 & 1 & 0,7 & 0,4 & 0,7 \\
0,4 & 0,8 & 0 & 0,4 & 0 & 0 & 0 & 0 & 1 & 0,4 & 0,9 \\
0,5 & 0,5 & 0 & 0,5 & 0 & 0 & 0 & 0 & 0 & 1 & 0,9 \\
0,4 & 0,4 & 0 & 0,4 & 0 & 0 & 0 & 0 & 0 & 0,4 & 1
\end{array}\right]
$$

Further we find: $V(x 1)=0(\mathrm{x} 1) \mathrm{v} 0(\mathrm{x} 2) \mathrm{v} 0(\mathrm{x} 3) \mathrm{v} 0(\mathrm{x} 4) \mathrm{v} 0(\mathrm{x} 5) \mathrm{v}$ $0(\mathrm{x} 6) \mathrm{v} 0(\mathrm{x} 7) \mathrm{v} 0(\mathrm{x} 8) \mathrm{v} 0(\mathrm{x} 9) \mathrm{v} 0(\mathrm{x} 10) \mathrm{v} 0(\mathrm{x} 11) \mathrm{v} 0.4(\mathrm{x} 1 \mathrm{x} 3 \mathrm{x} 5 \mathrm{x} 6 \mathrm{x} 7 \mathrm{x} 8 \mathrm{x} 9)$ $\mathrm{v} 0,4(\mathrm{x} 2 \mathrm{x} 3 \mathrm{x} 5 \mathrm{x} 6 \mathrm{x} 7 \mathrm{x} 8 \mathrm{x} 9) \mathrm{v} 0,4(\mathrm{x} 3 \mathrm{x} 4 \mathrm{x} 5 \mathrm{x} 6 \mathrm{x} 7 \mathrm{x} 8 \mathrm{x} 9) \mathrm{v} 0,4(\mathrm{x} 3 \mathrm{x} 5 \mathrm{x} 6 \mathrm{x} 7 \mathrm{x} 8$ $\mathrm{x} 9 \mathrm{x} 10) \mathrm{v} 0,4(\mathrm{x} 3 \mathrm{x} 5 \mathrm{x} 6 \mathrm{x} 7 \mathrm{x} 8 \mathrm{x} 9 \mathrm{x} 11) \mathrm{v} 0,5(\mathrm{x} 1 \mathrm{x} 2 \mathrm{x} 3 \mathrm{x} 4 \mathrm{x} 5 \mathrm{x} 6 \mathrm{x} 7 \mathrm{x} 8 \mathrm{x} 9 \mathrm{x} 11)$ $\mathrm{v} 0,5(\mathrm{x} 1 \times 2 \times 3 \times 5 \times 6 \times 7 \times 8 \times 9 \times 10 \times 11) \mathrm{v} 1(\mathrm{x} 1 \times 2 \times 3 \times 4 \times 5 \times 6 \times 7 \times 8 \times 9 \times 10$ $\mathrm{x} 11)=0,4$. It means that the structural stability degree of the studied model is at the level of 0,4 that classifies model as so-so steady.

\section{B. The Topological Aanalysis of Model Structure}

The first step of topological analysis is to determine the interaction of the concepts on each other, and also obtaining information on implicit mutual effects between the concepts [9]. Results of system indicators calculation of FCM are presented (Table I). 
TABLE I. SYSTEM INDICATORS

\begin{tabular}{|c|c|c|c|c|c|c|}
\hline & $\begin{array}{c}\text { Consonance } \\
\text { of influence } \\
\text { of vertex } \\
\text { on system }\end{array}$ & $\begin{array}{c}\text { Consonance } \\
\text { of influence } \\
\text { of system } \\
\text { on vertex }\end{array}$ & $\begin{array}{c}\text { Disso- } \\
\text { nance of } \\
\text { influence } \\
\text { of vertex } \\
\text { on system }\end{array}$ & $\begin{array}{c}\text { Disso- } \\
\text { nance of } \\
\text { influence } \\
\text { of system } \\
\text { on vertex }\end{array}$ & $\begin{array}{c}\text { Influence } \\
\text { of vertex } \\
\text { on system }\end{array}$ & $\begin{array}{c}\text { Influence } \\
\text { of system } \\
\text { on vertex }\end{array}$ \\
\hline$x_{1}$ & 0,72 & 0,34 & 0,28 & 0,66 & 0,05 & 0,05 \\
\hline$x_{2}$ & 0,68 & 0,52 & 0,32 & 0,48 & $-0,005$ & 0,25 \\
\hline$x_{3}$ & 0,79 & 1 & 0,21 & 0 & 0,06 & 0,07 \\
\hline$x_{4}$ & 0,72 & 0,22 & 0,28 & 0,78 & 0,22 & $-0,18$ \\
\hline$x_{5}$ & 0,75 & 1 & 0,25 & 0 & 0,10 & 0,05 \\
\hline$x_{6}$ & 0,68 & 1 & 0,32 & 0 & 0,17 & 0,03 \\
\hline$x_{7}$ & 0,72 & 1 & 0,28 & 0 & 0,12 & 0,09 \\
\hline$x_{8}$ & 0,7 & 1 & 0,3 & 0 & 0,3 & 0 \\
\hline$x_{9}$ & 0,72 & 1 & 0,28 & 0 & 0,08 & 0,13 \\
\hline$x_{10}$ & 0,72 & 0,35 & 0,28 & 0,65 & $-0,06$ & $-0,08$ \\
\hline$x_{11}$ & 0,67 & 0,44 & 0,33 & 0,56 & $-0,13$ & 0,5 \\
\hline
\end{tabular}

The data is analysed: the vertex $x_{10}$ is inconsistent but balanced as it attenuates FCM (-0.06), but equally and FCM attenuates this vertex $(-0.08)$, ie, the node $x_{10}$ with a negative effect that appears to be two-sided, there being no negative cycles. If there were negative cycles in the FCM, then with positive external action on the vertices, which make up the cycle, their negative influence on the FCM over time increased. If the vertices that make up the cycle negatively affect, then this would result in a positive effect for the system as a whole. The greatest impact on the FCM side is the vertex $x_{11}(0.51), x_{9}(0.13), x_{7}(0.09)$, $x_{6}(0,03), x_{5}(0,05), x_{3}(0.07), x_{2}(0.25), x_{1}(0.05)$. High probability of, that influence of FCM on these nodes is able to damp any negative effect from outside. That is, if the operator intends to want to have any long-term action thereon, it should be made to be influenced by indirect acting on the vertices $x_{11}$ and $x_{2}$. By analyzing all the values of the consonance and dissonance of the effect of all the nodes on the FCM, it is possible to conclude on the fact, all relationships between the vertices of the experts are set correctly and re-matrixes of them are not necessary.

The second step is the detection of significant model relationships [10]. For this, the values of the links between the vertices are to be transformed as follows:

1) if the initial value is in the range of $[1,0)$, then is given «- $1 »$; 2 ) if the initial value is in the range of $[0,0,5)$, then is given $« 0 »$; 3 ) if the initial value is in the range of $[0,5,1)$, then is given «1».

Next, the calculation of the simplex dimensionality of the complex $\mathrm{K}_{x}(Y ; \lambda)$ and $\mathrm{K}_{y}\left(X ; \lambda^{*}\right)$ is sequentially carried out. The first structural vector of a complex $\mathrm{K}_{x}(Y ; \lambda)$ and connectivity value for $\mathrm{K}_{x}(Y ; \lambda)$ is defined:

$q=3, \mathrm{Q}_{3}=1,\left\{x_{8}\right\}$

$q=2, \mathrm{Q}_{2}=2,\left\{x_{8}\right\},\left\{x_{4}\right\},\left\{x_{7}\right\}$;

$q=1, \mathrm{Q}_{1}=5,\left\{x_{8}, x_{5}\right\},\left\{x_{6}, x_{4}\right\},\left\{x_{7}, x_{9}\right\},\left\{x_{10}\right\}$;

$q=0, \mathrm{Q}_{0}=3$, \{everything, except $x_{1}, x_{2}$ и $\left.x_{3}\right\}$.

At the level $q=1$ there is a coherent component $\left(\left\{x_{8}, x_{5}\right\}\right.$, $\left.\left\{x_{6}, x_{4}\right\},\left\{x_{7}, x_{9}\right\}\right)$ this means that if the control is applied to $x_{5}$ and $x_{8}$, they respond to this action. As target concepts, $x_{8}$ nodes may be selected. Furthermore, the elimination of such nodes $x_{4}$ and $x_{7}$ from the system is equal to the destruction of the system. In this case, special attention must be paid to the nodes $x_{1}, x_{2}$ and $x_{3}$, since they can be a problem to effectively interact with the vertices between each other. Connectivity value for $\mathrm{K}_{y}\left(X, \lambda^{*}\right)$ :

$q=3, \mathrm{Q}_{3}=2,\left\{y_{2}\right\},\left\{y_{11}\right\}$;

$q=2, \mathrm{Q}_{2}=2,\left\{y_{2}\right\},\left\{y_{11}\right\},\left\{y_{4}\right\},\left\{y_{10}\right\}$;

$q=1, \mathrm{Q}_{1}=3,\left\{y_{1}\right\},\left\{y_{2}\right\},\left\{y_{11}\right\},\left\{y_{4}\right\},\left\{y_{10}\right\},\left\{y_{3}, y_{7}\right\},\left\{y_{6}\right\}$; $q=0, \mathrm{Q}_{0}=3$, \{everything, except $\left.y_{8}\right\}$.

So, the analysis has shown that as target factors vertices of $x_{2}$ and $x_{11}$ can be chosen. At the same time it is necessary to pay special attention to $x_{8}$ vertice. The greatest value for the studied FCM is played by vertices: $x_{2}, x_{4}, x_{10}$ and $x_{11}$.

\section{COMPUTING EXPERIMENT}

Simulation modeling has been applied to carrying out a computing experiment. The plan of an experiment including the choice of FCM concepts for definition of development scenarios of CIO by input of simple and complex impulses is developed. As a result of work of experts concepts in which revolting influences are important and most interesting to understanding of development of the situation are defined and/or monitoring of which is most important for tracking a condition of CIO.

Next, the fuzzy cognitive model simulation was carried out, as a result of which different situations of developing situations were constructed, related to the control of the NPP, in order to reduce the negative trends and/or enhance the positive trends. The resulting scenarios respond to the question: «what will occur with the system at time $t(n+1)$ if...».

A fragment of a computer experiment (CE) plan for FCM, consisting the most specific scenarios of the development of FCM is presented (Table II).

TABLE II. FRAGMENT OF THE CE PLAN

\begin{tabular}{|c|c|c|c|c|c|c|c|c|c|c|c|c|}
\hline \multirow{2}{*}{$\begin{array}{l}\text { Sce- } \\
\text { nario }\end{array}$} & \multirow{2}{*}{ Impulse } & \multicolumn{11}{|c|}{ Vertices } \\
\hline & & $x_{1}$ & $x_{2}$ & $x_{3}$ & $x_{4}$ & $x_{5}$ & $x_{6}$ & $x_{7}$ & $x_{8}$ & $x_{9}$ & $x_{10}$ & $x_{11}$ \\
\hline № 1 & $\begin{array}{c}q_{3}=-10 \\
q_{11}=-10\end{array}$ & & & -10 & & & & & & & & - \\
\hline № 2 & $\begin{array}{c}q_{2}=-10 \\
q_{3}=-10 \\
q_{4}=10\end{array}$ & & -10 & -10 & 10 & & & & & & & \\
\hline № 3 & $\begin{array}{c}q_{3}=10 \\
q_{11}=10\end{array}$ & & & 10 & & & & & & & & 10 \\
\hline № 4 & $\begin{array}{c}q_{5}=10 \\
q_{8}=10 \\
q_{10}=10\end{array}$ & & & & & 10 & & & 10 & & 10 & \\
\hline
\end{tabular}

Scenario No. 1. The impulse comes to two vertices. We ask a question: «What will be the system if we reduce $x_{3}=-10 \%$ and $x_{11}=-10 \%$ ?» (Fig. 2). 


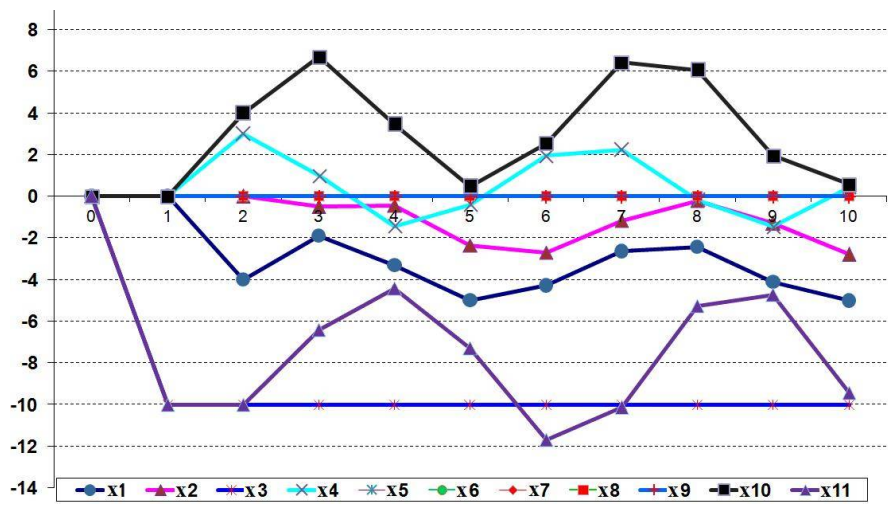

Fig. 2. Scenario №1

Analysis: decrease of $x_{3}$ and $x_{11}$ involves increase in personal responsibility of employees $\left(x_{10}\right)$ and human factor $\left(x_{4}\right)$. At the same time sharp reduction of safety of the NPP safety $\left(x_{11}\right)$ is observed.

Scenario No. 2. The impulse comes to three vertices. We ask a question: «What will be the system if we reduce $x_{2}=-10 \%, x_{3}$ $=-10 \%$ and increase $x_{4}=10 \%$ ?» (Fig. 3).

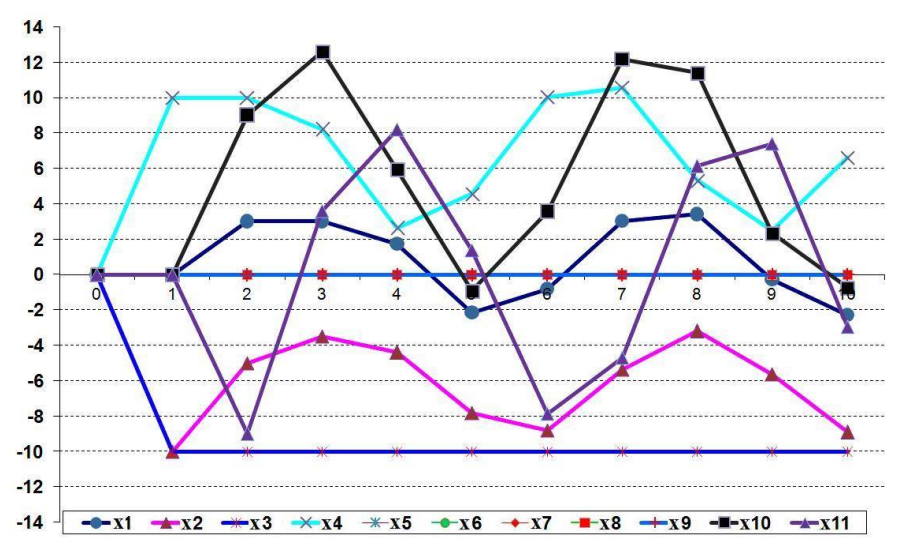

Fig. 3. Scenario №2

Analysis: at decrease of $x_{2}, x_{3}$ and increase in $x_{4}$ on a step 3 increase in personal responsibility of employees $\left(x_{10}\right)$ by $13 \%$, increase in influence of a human factor $\left(x_{4}\right)$ by $9 \%$ and also NPP safety $\left(x_{11}\right)$ by $3 \%$ is observed. However on the following steps sharp fluctuations practically to values of all vertices are observed, as speaks about «negativity» of this scenario.

Scenario No. 3. The impulse comes to two vertices. We ask a question: «What will be the system if we increase $x_{3}=10 \%$ and $x_{11}=10 \%$ ?» (Fig. 4).

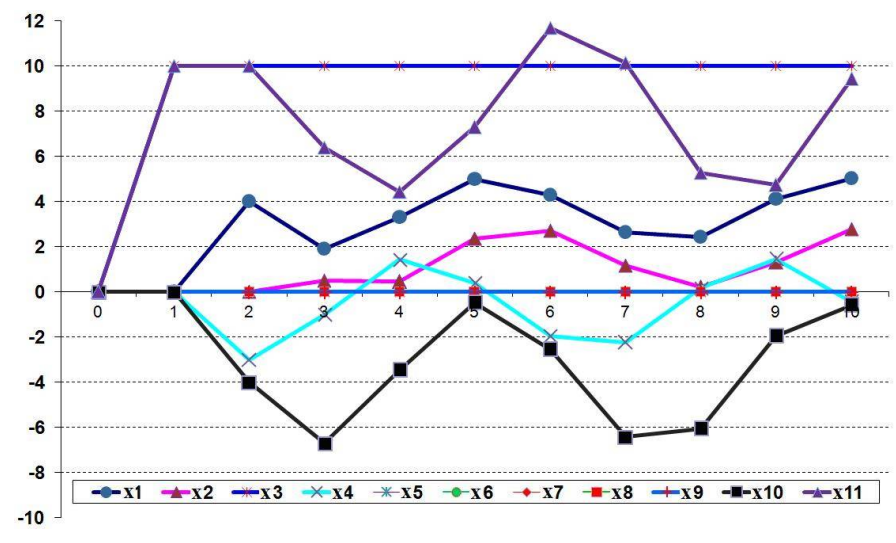

Fig. 4. Scenario №3

Analysis: increase in $x_{3}$ and $x_{11}$ on a step 5 leads to increase monitoring system $\left(x_{1}\right)$ for $5 \%$, and to increase the decisionmaking speed $\left(x_{2}\right)$ for $3 \%$. At the same time personal responsibility of employees $\left(x_{10}\right)$ sharply decreases by $-7 \%$ and a human factor $\left(x_{4}\right)$.

Scenario No. 4. The impulse comes to three vertices. We ask a question: «What will be the system if we increase $x_{5}=10 \%$, $x_{8}=10 \%$ and $x_{10}=10 \%$ ?» (Fig. 5).

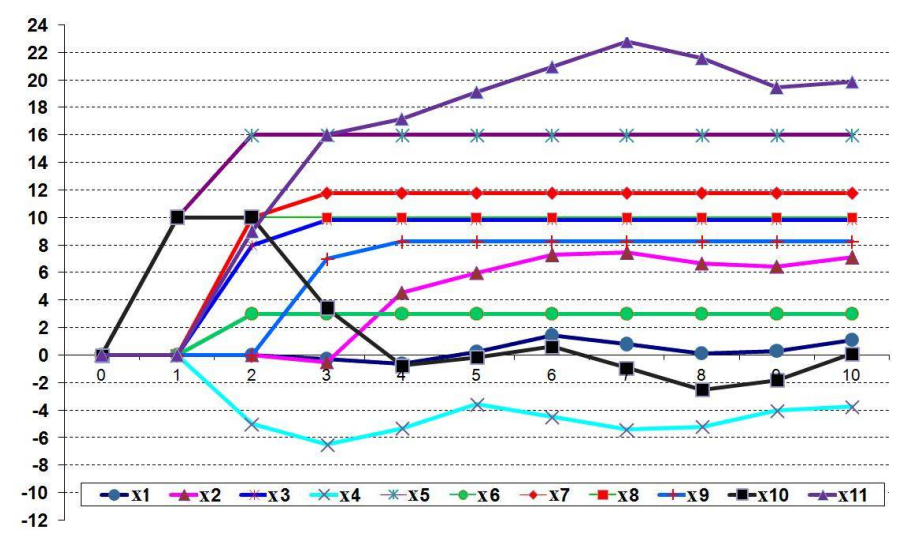

Fig. 5. Scenario №4

Analysis: at increase in $x_{5}, x_{8}$ and $x_{10}$ increase in values in all vertices except for gradual reduction of a human factor $\left(x_{4}\right)$, the monitoring system $\left(x_{1}\right)$ and personal responsibility of employees $\left(x_{10}\right)$ is observed.

Recommendation. The carried-out analysis of the considered scenarios has shown that scenarios No. 1 and No. 2 are «negative» and it isn't necessary to allow their realization, and scenarios No. 3 and No. 4 - are «positive».

\section{CONCLUSION}

Cognitive and simulation modeling is applied to studying of behavior of crucial objects on the example of nuclear power plants. The model of the organizational-control structure in the 
form of fuzzy cognitive model is offered for what a list of concepts is defined. The computing experiment is developed and conducted. Some results of the scenarios analysis of possible development of the situation are described, scenarios are developed by means of pulse modeling. It is shown that the offered fuzzy cognitive model combining quantitative and quality indicators, makes it possible to simulate a stable structure of a complex object for the purpose of adoption scientific and objective control decisions. The model can be a basis of development of the analytical monitoring instrument and on-line analysis of the current situation for the purpose of scientific previewing of risky, extreme situations, as a consequence, is sewn from catastrophes in the lifetime of such critically important objects as atomic power stations.

\section{REFERENCES}

[1] Lee D., Kim J. “Autonomous algorithm for safety systems of the nuclear power plant by using the deep learning". Advances in Intelligent Systems and Computing, Vol. 599, pp. 72-82, July 2017

[2] Rahman M.M., Field R.M. "Analysis of Primary Containment Capture System for the propose Advanced Modern 600 nuclear powerplant". Nuclear Engineering and Design, Vol. 324, pp. 196-201, December 2017

[3] Kalashnikov A.O., Yermilov Y.V., Choporov Y.V., Razinkin K.A., Barannikov N.I. "Ensuring the security of critically important objects and trends in the development of information technology". 25.399. 403. 10.5829/idosi.wasj.2013.25.03.13316. January 2013
[4] Krasov A.A. "Safety of crucial objects: integrated approach". Algoritm bezopasnosti, №2, pp. 4-9, May 2017

[5] Balanovskaya A.V., Volkodaeva A.V. "Information Security of Critically Important Objects in Automatic Technological Process Control Systems". Vestnik Samarskogo munitsipal'nogo instituta upravleniya, №1, pp. 74-81, Апрель 2017.

[6] Ginis L.A. "The use of fuzzy cognitive maps for the analysis of structure of social and economic system for the purpose of its sustainable development". Mediterranean Journal of Social Sciences, Vol. 6, Is. 3, S5, pp. 113-118, June 2015.

[7] Roberts F.S. "Discrete mathematical models with application to social, biological and environmental problems". Prentice-Hall, Inc. Englewoo Cliffs, New Jersey, 1976. - 496 p.

[8] Bozhenyuk A.V., Ginis L.A. "Analysis of problem oriented systems structure with uncertainty based on fuzzy graphs". III International Scientific Conference «Information Technologies in Science, Management, Social Sphere and Medicine» (ITSMSSM 2016): proceedings, Tomsk, Vol. 51, pp. 542-545, May 2016.

[9] Kolodenkova A.E., Khalikova E.A., Korobkin V.V., Gubanov N.G. "A method of project feasibility assessment on creation of information-control systems for complex technical objects on the basis of fuzzy cognitive modeling". International Journal of Control Theory and Applications, No. 9 (30), pp. 73-82, September 2016.

[10] Kolodenkova A.E. "Topological analysis of the structure of fuzzy cognitive model of project feasibility assessment to create of the information-control systems for complex technical objects”. Vestnik UGATU, Vol.20, №3(73), pp.129-136, September 2016. 